\title{
1 Temperature-related shifts in butterfly phenology depend on the
}

\section{2 habitat.}

3

$4 \quad$ Florian Altermatt

6 Eawag: Swiss Federal Institute of Aquatic Science and Technology, Department of Aquatic

7 Ecology, Überlandstrasse 133, CH-8600 Dübendorf, Switzerland.

8 Corresponding author: florian.altermatt@eawag.ch

9 Phone: +41587655592

11 Keywords: biodiversity monitoring, Lepidoptera, urban ecology, temperature change, flight

12 period, seasonal appearance, metacommunity, source-sink

13

14 manuscript length: $\mathbf{5 4 0 0}$ words

15 number of tables: 1

16 number of figures: 5

This document is the accepted manuscript version of the following article:

Altermatt, F. (2012). Temperature-related shifts in butterfly phenology depend on the habitat. Global Change Biology, 18(8), 2429-2438.

https://doi .org/10.1111/j.1365-2486.2012.02727.x 
17

18

19

\section{Abstract}

Many species are becoming active earlier in the season as the climate becomes warmer. In parallel to phenological responses to climate change, many species have also been affected by habitat changes due to anthropogenic land use. Since habitat type can directly affect microclimatic conditions, concurrent changes in climate and habitat could have interacting effects on the phenology of species. Temperature related shifts in phenology, however, have mostly been studied independent of habitat types. Here, I used long-term data from a highly standardized monitoring program with 519 transects to study how phenology of butterflies is affected by ambient temperature and habitat type. I compared forests, agricultural areas and settlements, reflecting three major land use forms, and considered butterfly species that were observed in all three of these habitats. Seasonal appearance of the butterflies was affected both by the ambient temperature and the habitat type. As expected, warmer temperatures led to an overall advancement of the appearance and flight period of most species. Surprisingly, however, phenology of species was delayed in settlement habitats, even though this habitat type is generally associated with higher temperatures. A possible explanation is dispersal among habitat types, such that source-sink effects affect local phenology. When there is little productivity in settlement areas, observed butterflies may have immigrated from forest or agricultural habitats and thus appear later in settlements. My findings suggest that a spill-over of individuals among habitats may affect phenology trends and indicate that phenological studies need to be interpreted in the context of habitat types. This becomes especially important when defining strategies to prevent or mitigate effects of climate and land-use changes on phenology and abundance of species. 


\section{Introduction}

Global climate change and habitat changes are altering the occurrence and abundance of species worldwide (Altermatt et al. 2008, IPCC, 2007, Parmesan \& Yohe, 2003, Thomas et al., 2004, Travis, 2003, Walther et al., 2002). Over the last decades, many habitats and continents have been strongly affected by a changing climate (Walther et al., 2002). Over the same time many landscapes have also changed due to intensification of agriculture, deforestation, or urbanization (Thomas et al., 2004, Warren et al., 2001). While climate and habitat change may go hand-in-hand, the consequences for local communities are not necessarily the same, and can either add up or diverge (Dale, 1997, Franco et al., 2006, Travis, 2003, Warren et al., 2001). Consequently, a comprehensive understanding of the individual and combined consequences of these two processes on communities is necessary to prevent or mitigate their negative effects.

Temperature increases over time are one of the most commonly studied aspects of global climate change, and subsequent phenological changes are reported for many organisms. Phenology often directly depends on temperature (Helmuth et al., 2005, Walther et al., 2002). For example, plants advanced flowering and seed-set in warmer years (Fitter \& Fitter, 2002, Steltzer \& Post, 2009), birds and other vertebrates have advanced their breeding season (Dunn \& Winkler, 1999, Walther et al., 2002), and seasonal appearance of many butterflies and other insects have advanced by up to several weeks on various continents in a period of pronounced warming since the late 1970's (Altermatt, 2010b, Forister \& Shapiro, 2003, Musolin, 2007, Roy \& Sparks, 2000, Walther et al., 2002).

In parallel, many habitats have been changing drastically, mostly due to anthropogenic influence (Fischer \& Lindenmayer, 2007). Globally, the transition of forests into agricultural lands and the development of grassland habitats into villages, towns and road infrastructure are some of the most common habitat transformations (Foley et al., 2005, Tilman et al., 
2001). These habitat transformations have large consequences for local organisms, since they affect the occurrence of resources, competitors or other key aspects of a species' life cycle (Fischer \& Lindenmayer, 2007, Warren et al., 2001). Consequently, the species communities in agricultural or urbanized habitats are often different and depleted compared to those of forested and other natural habitats. Habitat transformations can also modify the microclimate. Heat emission caused by domestic heating during winter and a reduced ambient cooling during the night due to temperature storage in concrete and asphalt warms up towns and urbanized areas (Fischer et al., 2012, Oke, 1982). Middle-sized and large cities form heat islands with higher average temperatures than their surroundings, which can directly affect the phenology of species (Defila \& Clot, 2001, Neil \& Wu, 2006).

Few studies addressed if warming and habitat type or habitat change have combined effects on phenology and population dynamics (Defila \& Clot, 2001, Warren et al., 2001). A limitation of these studies was that they only focused on one habitat or included different sets of species for different habitat types. For example, flowering period of the Horse Chestnut (Aesculus hippocastaneum) in the city of Geneva has advanced due to a combined effect of warming due to climate change and urbanization (Defila \& Clot, 2001). However, Horse Chestnut is not native to Central Europe, and is only planted in urbanized and developed areas and does not occur in other habitat types. Thus, phenological changes related to climate change or habitat type are hard to disentangle. In well-studied butterfly communities in Great Britain, population trends of different butterfly species were positively affected by warming but negatively affected by habitat change or habitat loss (Warren et al., 2001). However, habitat changes mostly affected the abundance and distribution of habitat specialists restricted to specific habitats such as heathlands, while mobile habitat generalists profited from the warming. 
From a conservation perspective, it is important to know if and how habitat type and climate change related temperature changes affect phenologies of species (O'Connor et al., 2012). Phenological changes can have large consequences for ecosystems. The life cycle of many insects depends on a close matching with the phenology of their host plant, and mismatches, especially changes in voltinism (Altermatt, 2010a), may result in disruption of plant-insect interactions or host-parasite interactions (Jönsson et al. 2009, Memmott et al. 2007).

Here, I used long-term data from a randomized monitoring program conducted in parts of Switzerland to study how phenology of butterflies is affected by ambient temperature and habitat type. I compared forests, agricultural areas and settlements, reflecting three major land use forms in Central Europe (Fig. 1), and only considered butterfly species that were observed in all three of these habitat types. The three habitat types remained constant during the whole study period, and also have been relatively unchanged for the preceding decades, excluding transitory effects that may occur during the transformation of one habitat type into another.

\section{Material and Methods}

Study area. The study area is the Swiss canton of Aargau (centre coordinates: $47^{\circ} 22^{\prime} 31^{\prime \prime}$ N $\left./ 8^{\circ} 05^{\prime} 03^{\prime}, \mathrm{E}\right)$. It is located in the northern part of Switzerland, and belongs geologically to the Jura mountains and the Central Plateau of Switzerland. The canton of Aargau has an area of $1404 \mathrm{~km}^{2}$. The vertical extension ranges from $260 \mathrm{~m}$ above sea level to $908 \mathrm{~m}$ above sea level. About $490 \mathrm{~km}^{2}$ (35\%; Fig. 1) of its area are forested, $618 \mathrm{~km}^{2}$ (44\%) are used for agriculture, and $217 \mathrm{~km}^{2}$ (15\%) are developed and consist of road and railway infrastructure, villages and towns (land cover values from 2005, Statistik Aargau, 2010). The remaining area is mostly open waters (ponds and streams) and marginal habitat types. 
113 Biodiversity monitoring project. In the whole canton of Aargau, biodiversity is monitored

114 in a long-term research project (Roth et al., 2008, Stapfer, 1996). The diversity of butterflies

115 has been measured since 1998 on a randomly placed, regular grid that covers the entire canton

116 (Fig. 1). In total 519 grid sites are included, about $20 \%$ of which are monitored annually. The

117519 grids are representatively covering the main habitat types in the study area $(34 \%$ of the

118 transects are in forests, $45 \%$ in agricultural areas, and $20 \%$ in settlement areas; see previous

119 paragraph on land cover estimates). This study focuses on all butterflies and burnet moths

120 (Lepidoptera: Papilionoidea: Papilionidae, Pieridae, Nymphalidae, Lycaenidae and

121 Zygaenoidea: Zygaeninae; in the following all referred to as "butterflies") recorded in that

122 monitoring program from 1998 to 2010.

123 Butterflies were recorded using standardized transect counts (method after Pollard et

124 al., 1995) along transects of $250 \mathrm{~m}$ length. Butterflies were recorded within $5 \mathrm{~m}$ to each side

125 of the transect line, and each site was visited 11 times per sampling year in regular time

126 intervals from April 21 to September 21. Transect samplings were only conducted when

127 meteorological conditions were favourable for butterflies to fly. All observed individuals

128 were identified to the species level. Some species were only recorded as species complex.

129 This refers to Leptidea sinapis and L. reali (here called Leptidea sinapis complex and treated

130 as one species), Colias hyale and C. alfacariensis (here called Colias hyale complex and

131 treated as one species), and Pieris brassicae, P. rapae and P. napi (here called Pieris sp. and

132 treated as one species). In total, 55,250 individuals of 50 butterfly species were recorded.

133 About $28 \%$ of the records are from forest habitats, $60 \%$ from agricultural habitats, and $12 \%$

134 from settlement habitats. These numbers are closely reflecting the coverage of the study area

135 by the three habitat types (see above), thus giving on average comparable butterfly densities

136 in these habitats. The higher number of individuals in the agricultural habitat is mostly driven 
137 by the most common species, Pieris sp. Here, I restrict myself to the 28 species that have been recorded in all three main types of habitats in the canton of Aargau (see next paragraph). The habitat directly surrounding each transect ( $0.25 \mathrm{ha})$ was classified using the

140 European CORINE Land Cover typology (CEC, 1994). I used level one of these categories to

141 characterise the habitat surrounding the transect, distinguishing agricultural habitats (arable

142 land, permanent crops and pastures; Fig. 1), forested habitats (forests and woodland shrub

143 vegetation), artificial surfaces (in the following called "settlement habitat", including urban

144 fabric, roads and railways and construction sites) and other classes (wetlands; $<2 \%$ of the sites

145 and thus excluded from further analyses). Each transect was assigned to one of these three

146 classes, based on the land cover class that covered $>50 \%$ of the transect. A few transects were

147 excluded from the following analyses because they could not be unambiguously assigned to

148 one land classes (i.e., when all three major habitat types were present and none of them

149 covered $>50 \%$ of the transect). I analysed how the habitat surrounding the transects affected

150 phenology of the butterfly species. I conducted all comparisons on the level of the whole

151 study area, and not on the scale of individual transects. Since transects were randomly placed

152 across the landscape, and the amount of observational efforts (i.e., number of transects) was

153 constant across the different years, I could use the data on the butterfly fauna and phenology

154 to be representative of the landscape level.

155 The fieldwork of the monitoring program was conducted by men doing their civilian

156 service. Each of them was carefully selected to maintain high quality standards. The civilian

157 servants received intensive training, and their field method and identification skills were

158 controlled continuously. They worked in the program fulltime and generally for multiple

159 seasons. The program was quality certified, following detailed procedures (Weber, 2008).

160 This included the collection of certain difficult-to-identify taxa to be double-checked by a

161 butterfly expert. The collection of specimens specifically targeted "difficult" groups (e.g., 
162 checkerspots, burnet moths or Lycaeniinae). Furthermore, $10 \%$ of all transects were monitored by two independent people using a blinded approach, meaning that the

164 fieldworkers did not know which transects were being double-monitored. This allowed

165 disentangling the (undirected) sampling error from possible individual bias. When an

166 individual bias occurred, all data of that particular observer were discarded, and the transects

167 were monitored again the following year. Altogether, these measures and the quality tests

168 (Weber, 2008) assured that the data fulfilled highest quality standards.

171 Temperature data. Three official weather stations of the Federal Office of Meteorology and

172 Climatology (MeteoSwiss) are located in close vicinity of the canton of Aargau. They are

173 located North-westward, Eastward and South-westward of the canton of Aargau (weather station “Basel/Binningen“, 47 32' N / 07 35' E, 316 m a.s.1.; "Bern/Zollikofen”, 46 59.4' N / $7^{\circ} 27.8^{\prime} \mathrm{E}, 553 \mathrm{~m}$ a.s.1., and “Zürich/Fluntern”, 47²2.7' N / 8 33.9' E, $556 \mathrm{~m}$ a.s.1.). I used monthly mean values of homogenized air-temperature data (Begert et al., 2005) averaged

177 over the three weather stations and calculated annual mean spring temperature (March to

178 May) and mean summer temperature (June to August) for the years 1998 to 2010. I decided $a$ priori on the meteorological definition of spring and summer, as many insect species can be grouped in to "spring" or "summer" species. This coarse classification may not capture all phenological details. To compare how the flight period of individual species matches with the

182 spring and summer period respectively, I refer to the detailed phenograms of all butterfly

183 species, published in Altermatt et al. (2006).

185 Statistical analyses. Two different phenological response variables were calculated, one 186 describing the phenological timing of the flight period (appearance), and one describing a 
187 phenological state (flight-period length). Appearance is the date of the first $25 \%$ of the individuals for each species observed during the entire flight period per year. The use of this 25 th percentile instead of the date of the first appearance or other phenological measures describing the onset of flight periods is recommended because it is not biased by variation in sampling effort or population abundance (van Strien et al., 2008). Flight-period length was

192 calculated for each species as the range (in days) of all records (in Julian dates). Essentially, it 193 is the maximum time period within a season used by adults. Contrary to appearance, flightperiod length is sensitive to population size and sampling efforts, and is thus more difficult to 195 interpret.

I used paired Wilcoxon signed-rank tests to compare the appearance and flight-period

197 length of species across the three different habitat types. With this test I compared the overall

198 mean value of the phenological response variables for each butterfly species in each habitat,

199 to test if phenology differed between the habitats. As a non-parametric test, it makes few

200 assumptions and serves my main purpose, namely comparing if habitat type affects

201 phenology.

I then ran linear models (ANCOVAs) to predict how annual appearance of each species

203 (at the landscape level, and not at the transect level) is affected by habitat type (agriculture, 204 forest, and settlement), annual mean spring or mean summer temperature and the interaction 205 between habitat type and temperature. I was mostly interested in species-specific parameters 206 on the slope and intercept of the predicted date of appearance relative to either spring or 207 summer temperature, and less in the p-values for different species (Crawley, 2002). A 208 positive or negative slope indicated if a species postponed or advanced its seasonal 209 appearance with increasing temperature and if and how this depended on habitat type. The 210 intercept-comparison across different habitat types (to test on the effect of habitat type) was 211 coerced to the mean temperature across all years (for an evaluation and justification of this 
212

method see Schielzeth, 2010). Thereby, the intercept comparison was done at a biologically meaningful temperature (which it would not be at an intercept comparison at 0 , meaning at $\left.0{ }^{\circ} \mathrm{C}\right)$. Parameter values of all models are given for all species.

Additionally, I analysed the data using a mixed-effect model approach. Detailed justification, description and results of the mixed model approach are given in the supporting information file (Fig. S2, section "b) Extended analysis using mixed-effect models"). The results and conclusions of the mixed-effect model approach were quantitatively and qualitatively highly similar to the main analyses. All analyses were conducted in R 2.12.1 (R Development Core Team, 2010).

\section{Results}

Mean temperature in the study area ranged from $8.64{ }^{\circ} \mathrm{C}$ to $11.43{ }^{\circ} \mathrm{C}$ (spring) and from $17.57{ }^{\circ} \mathrm{C}$ to $21.73{ }^{\circ} \mathrm{C}$ (summer) over the years $1998-2010$ (Fig. 2). There was no significant change in temperature over time (spring: $\mathrm{F}_{1,11}=0.05, \mathrm{R}^{2}=0.001, \mathrm{p}=0.82$; summer: $\mathrm{F}_{1,11}=0.13$, $\mathrm{R}^{2}=0.01, \mathrm{p}=0.73$ ). Coinciding with an exceptional heat wave in Europe (Schar et al., 2004), mean summer temperature in 2003 was much higher than in all other years.

The date of appearance of many butterfly species significantly correlated with annual mean spring temperature (Tab. 1a) or summer temperature (Tab. 1b), and habitat type. The interaction of temperature and habitat type on date of appearance was significant for four species (Tab. 1). Slope and intercept estimates of the ANCOVA models are given for each species and habitat type (Tab. 1). The appearance of 14 of the 28 butterfly species significantly or marginally significantly advanced to an earlier date when the spring or summer temperature was warmer (Tab. 1), and only two species significantly postponed their appearance to a later date. Furthermore, there was also an overall significant trend in advancing the flight period over time. The slope of a linear regression between year and 
annual $25 \%$ appearance was negative for 24 of the 28 species, showing that the advancement in appearance over time was significant across all species (sign-test, $\mathrm{p}=0.0002$ ).

Using the mean across all years, appearance of the 28 butterfly species was significantly later in the season in settlement habitats compared to forested and agricultural habitats (Bonferroni-corrected paired Wilcoxon signed-rank tests between the habitat types: settlement vs. agriculture, mean difference $=9.7$ days, $V=324, p=0.01$; settlement vs. forest, mean difference $=11.8$ days, $\mathrm{V}=67, \mathrm{p}=0.004$; forest vs. agriculture, mean difference $=2.1$ days, $\mathrm{V}=189, \mathrm{p}=0.76$; Fig. 3). The later appearance of species in settlement habitat compared to either forested or agricultural areas remained significant when conducting the same analysis on a subset of 14 species that were found on at least 25 transects in each habitat type (Wilcoxon signed-rank tests between the habitat types: settlement vs. agriculture, $\mathrm{V}=20$, $\mathrm{p}=0.04$; settlement vs. forest, $\mathrm{V}=98, \mathrm{p}=0.002$; Fig. $\mathrm{S} 1$ ).

Across all years, length of flight period of the 28 butterfly species was significantly shorter in settlement habitats compared to agricultural habitats (Bonferroni-corrected paired Wilcoxon signed-rank test: settlement vs. agriculture, $V=385.5, p<0.001$; Fig. 4) but not significantly different in settlement habitats compared to forested habitats ( $V=98.5, p=0.1$ ) and forested habitats compared to agricultural habitats $(\mathrm{V}=296, \mathrm{p}=0.1)$.

In a last step, I used the estimates of the regression models (Tab. 1) to predict the expected changes in appearance with a $1{ }^{\circ} \mathrm{C}$ warming of the annual spring or summer temperature and the habitat type. The model predictions suggest a mean shift of the date of appearance to an earlier date of 5 days when spring temperature increases by $1{ }^{\circ} \mathrm{C}$ (Fig. $5 \mathrm{~A}$ ), but no such shift is predicted with increasing summer temperature (Fig. 5B). The shift in appearance is predicted to be equal among the three habitat types. 


\section{Discussion}

263 Until now, little has been known about how habitat type and climate change interact to affect 264 phenology. Without taking into account different responses among habitats, managing and 265 mitigating the effects of climate change on phenology may be biased toward particular 266 ecosystems. Using a long-term data set from a standardized monitoring program (Fig. 1), I

267 found that seasonal appearance of butterflies was significantly correlated with mean ambient 268 seasonal temperature, habitat type, as well as an interaction of temperature and habitat type 269 (Tab. 1). As expected, warmer temperatures lead to an advancement of the appearance for most species, and the effect of warming on appearance was most pronounced for spring temperatures (Tab. 1). However, appearance of butterfly species was not shifted earlier in the

272 settlement habitats than in other habitats (Fig. 3), despite the higher temperatures associated 273 with this habitat type (Neil \& Wu, 2006, Oke, 1982). In fact, butterflies of the same species started flying significantly later in settlement habitats compared to agricultural and forest habitats (Fig. 3). Local population dynamics could explain species' later appearance in settlement than

277 agricultural or forest areas. The influence of population effects on phenology has been 278 recently documented for birds and insects, where overall regional declines in abundances masked phenological responses to climate change (Ellwood et al., 2011, Miller-Rushing et $a l .$, 2008). Here, I suggest that the dispersal of butterflies may result in their later appearance

281 in settlement habitats. Butterfly individuals from agricultural and forested habitats could 282 immigrate into (suboptimal) settlement habitats. With a temporal delay associated with such 283 dispersal, the observed phenological variables would be postponed in settlement habitats, 284 thereby causing an interaction of warming and habitat type on the observation of individuals. 285 Thus, in mobile animals effects consistent with source-sink dynamics may affect observed 
phenological trends. Such an effect is not expected for immobile plant individuals, where warming and urbanization are both consistently advancing phenology (Defila \& Clot, 2001).

The three habitat types considered here are not equally suitable for all butterfly species,

and some habitats provide better resources than others. In particular, the settlement habitat is

suboptimal for many species (Schweizerischer Bund für Naturschutz, 1987). The reduced suitability of settlement habitats is supported by a shorter total flight period therein (Fig. 4). A shorter flight-period could indicate a smaller population size or a shorter life-span, but can also be an artefact of reduced sampling effort. While it is not possible to disentangle these three mutually non-exclusive explanations, I suggest that at least part of the shorter flightperiod length is due to a smaller population size of butterflies in settlement habitats. In a recent paper, Forister et al. (2011) observed that declines in population size of many butterfly species result in shorter flight-period lengths. Thus, the shorter flight-period lengths observed here in settlement habitats are consistent with a smaller populations, as observed in another butterfly system. An inequality in habitats can create source-sink population dynamics (Brown \& Kodrick-Brown, 1977, Pulliam, 1988). In such a scenario, large population sizes

301 in one habitat and subsequent dispersal due to random or density-dependent dispersal may

302 lead to a migrant driven increase in population size in another locality at a later time point (Brown \& Kodrick-Brown, 1977). It is well-known that many butterflies live in patchy habitats, and dispersal among patches creates metacommunity dynamics (Ehrlich \& Hanski, 2004, Hanski \& Gaggiotti, 2004). Also, source-sink dynamics have been documented for 306 butterflies (Boughton, 1999, Harrison et al., 1988), yet the consequences for phenology have 307 not been examined. I cannot directly show the occurrence of source-sink dynamics. However, with source-sink dynamics, possibly coupled with age-dependent dispersal, we expect to see a shift in seasonal appearance of butterflies across different habitats driven by seasonal movement patterns and not by developmentally constrained phenology per se. Agricultural or 
311 forested areas may act as source populations, from which individuals of the same species

312 relocate into settlement areas at a later stage of their adult live. The settlement areas are

313 generally less suitable for butterflies (Warren et al., 2001), and may be analogous to an

314 ecological trap as observed in other species (Battin, 2004, Boal \& Mannan, 1999).

315 Furthermore, differences in the observation of organisms between different habitats may not

316 only be interpreted as phenological differences, but could also indicate sink-source dynamics.

317 While I did not have data on local dispersal of these butterflies, females of some of

318 these species are known to shift from local dispersal during early adulthood to longer-distance

319 dispersal in later life in order to lay remaining eggs at more distant localities (Schweizerischer

320 Bund für Naturschutz, 1987). Also, settlement areas are known to provide important nectar

321 sources during the second half of the summer, when agricultural crops and pastures are

322 harvested and cease to function as nectar sources. This could directly induce shifts in habitats, and act as an evolutionary strategy to colonize new areas.

I could exclude that species-specific restrictions to one habitat type are causing the observed pattern, by comparing the same 28 butterfly species across all three habitats. All species were observed in all habitat types, and as mostly generalist species can reproduce in a variety of habitats. By using a phenological variable that does not appear to be biased by population size (van Strien et al., 2008), I ensured that the difference in seasonal appearance among the habitats is not an artefact of different population sizes. However, my study indicates that phenological studies based on observations of mobile adults may not be able to

331 account for dispersal among localities, and individuals observed locally may not necessarily 332 reflect local phenologies. While appearance between the three habitat types was significantly different for many

334 butterfly species (Fig. 3), flight period length was only significantly different among settlement and agricultural habitats (Fig. 4). However, and contrary to appearance, flight 
period lengths may be affected by population sizes, which could interfere with phenological habitat effects.

The predicted magnitude of shifts in flight period (Fig. 5) was consistent with other studies that related onset of flight periods with temperature (Altermatt, 2010b, Forister \& Shapiro, 2003, Roy \& Sparks, 2000). The herein observed higher number of significant relationships between appearance and spring temperature versus appearance and summer temperature is in accordance with these previous findings that spring temperature has a larger influence on flight period than summer temperature. I also found an overall significant temporal change in appearance, with 24 of 28 species advancing their seasonal appearance over the 13 years. The advancement of individual species was not always significant, probably due to the relatively short time period over which the monitoring program was conducted (1998-2010). During the same time period, no significant temporal trend in mean spring and summer temperature was observed (Fig. 2). This trend does not suggest that temperature in Central Europe did not increase since 1998, but the high interannual variance in mean temperature and some extreme hot years (e.g., 2003) may have masked long-term trends. Many studies have shown that temperature in Central Europe increased significantly, especially since the 1980 's, and the years from 1998 onwards were among the warmest ever measured (CH2011, 2011, Schar et al., 2004).

Since changes in phenology are often compared over several decades during which concurrent habitat changes are likely or even documented (Altermatt, 2010b, Warren et al., 2001), the conclusions of such studies could be affected by a dependence of phenology on habitat type. My findings indicate that phenological studies need to be interpreted in the context of the habitat type, as conversions of habitats may interact with temperature-related shifts in flight period. For example, habitat changes such as urbanization may not only reinforce (Defila and Clot, 2001) but also mask phenological changes due to climate change. 
The consideration of habitat type when looking at changes in phenology is especially important when defining strategies to prevent or mitigate effects of climate and land-use changes on phenology and abundance of species.

Acknowledgements I thank all young men who collected the butterfly data during their alternative civilian service, Isabelle Floess, Matthias Plattner, Tobias Roth and Darius Weber for providing the raw data, and Annette Bieger for help with the data entry. Comments from Jeffrey M. Diez, Jay Fitzsimmons and two anonymous reviewers improved the manuscript. The "Abteilung Landschaft und Gewässer" of the canton of Aargau gave me the permission to use the data of the biodiversity monitoring program. A generous grant by the Emilia Guggenheim-Schnurr foundation enabled the data entry.

\section{References}

Altermatt F (2010a) Climatic warming increases voltinism in European butterflies and moths. Proceedings of the Royal Society B, 277, 1281-1287.

Altermatt F (2010b) Tell me what you eat and I'll tell you when you fly: diet can predict phenological changes in response to climate change. Ecology Letters, 13, 1475-1484.

Altermatt F, Fritsch D, Huber W, Whitebread S (2006) Die Gross-Schmetterlingsfauna der Region Basel, Basel, Entomologische Gesellschaft Basel.

Altermatt F, Pajunen VI, Ebert D (2008). Climate change affects colonisation dynamics in a metacommunity of three Daphnia species. Global Change Biology 14:1209-1220.

Battin J (2004) When good animals love bad habitats: Ecological traps and the conservation of animal populations. Conservation Biology, 18, 1482-1491.

Begert M, Schlegel T, Kirchhofer W (2005) Homogenous temperature and precipitation series of Switzerland from 1864 to 2000. International Journal of Climatology, 25, 65-80. 
Boal CW, Mannan RW (1999) Comparative breeding ecology of Cooper's hawks in urban and exurban areas of southeastern Arizona. Journal of Wildlife Management, 63, 7784.

Boughton DA (1999) Empirical evidence for complex source-sink dynamics with alternative states in a butterfly metapopulation. Ecology, 80, 2727-2739.

Brown JH, Kodrick-Brown A (1977) Turnover rates in insular biogeography: Effect of immigration on extinction. Ecology, 58, 445-449.

CEC (1994) CORINE land cover. Technical guide. pp Page, Luxembourg, Office for Official Publications of European Communities.

CH2011 (2011) Swiss Climate Change Scenarios CH2011. pp Page, Zurich.

Crawley MJ (2002) Statistical computing. An introduction to data analysis using S-Plus, Chichester, Wiley.

Dale VH (1997) The relationship between land-use change and climate change. Ecological Applications, 7, 753-769.

Defila C, Clot B (2001) Phytophenological trends in Switzerland. International Journal of Biometeorology, 45, 203-207.

Dunn PO, Winkler DW (1999) Climate change has affected the breeding date of tree swallows throughout North America. Proceedings Of The Royal Society Of London Series B-Biological Sciences, 266, 2487-2490.

Ehrlich PR, Hanski I (2004) On the wings of checkerspots, Oxford, Oxford University Press.

Ellwood E, Diez J, Ibáñez I, Primack R, Kobori H, Higuchi H, Silander J (2011) Disentangling the paradox of insect phenology: are temporal trends reflecting the response to warming? Oecologia, 1-11.

Fischer EM, Oleson KW, Lawrence DM (2012) Contrasting urban and rural heat stress responses to climate change. Geophys. Res. Lett., 39, L03705. 
Fischer J, Lindenmayer DB (2007) Landscape modification and habitat fragmentation: a synthesis. Global Ecology and Biogeography, 16, 265-280.

Fitter AH, Fitter RSR (2002) Rapid changes in flowering time in British plants. Science, 296, 1689-1691.

Foley JA, Defries R, Asner GP et al. (2005) Global consequences of land use. Science, 309, $570-574$.

Forister ML, Jahner JP, Casner KL, Wilson JS, Shapiro AM (2011) The race is not to the swift: Long-term data reveal pervasive declines in California's low-elevation butterfly fauna. Ecology, 92, 2222-2235.

Forister ML, Shapiro AM (2003) Climatic trends and advancing spring flight of butterflies in lowland California. Global Change Biology, 9, 1130-1135.

Franco AMA, Hill JK, Kitschke C et al. (2006) Impacts of climate warming and habitat loss on extinctions at species' low-altitude range boundaries. Global Change Biology, 12, $1545-1553$.

Hanski I, Gaggiotti OE (eds) (2004) Ecology, genetics and evolution of metapopulations, Amsterdam, Elsevier Academic Press.

Harrison S, Murphy DD, Ehrlich PR (1988) Distribution of the Bay checkerspot butterfly, Euphydryas editha bayensis: evidence for a metapopulation model. American Naturalist, 132, 360-382.

Helmuth B, Kingsolver JG, Carrington E (2005) Biophysics, physiologicalecology,and climate change: Does mechanism matter? In: Annual Review of Physiology. pp Page. Palo Alto, Annual Reviews.

IPCC (2007) Climate Change 2007: The Physical Science Basis. Summary for Policymakers, Geneva, WMO and UNEF. 
Jönsson AM, Appelberg G, Harding S, Bärring L (2009) Spatio-temporal impact of climate change on the activity and voltinism of the spruce bark beetle, Ips typographus. Global Change Biology, 15, 486-499.

Memmott J, Craze PG, Waser NM, Price MV (2007). Global warming and the disruption of plant-pollinator interactions. Ecology Letters 10:710-717.

Miller-Rushing AJ, Lloyd-Evans TL, Primack RB, Satzinger P (2008) Bird migration times, climate change, and changing population sizes. Global Change Biology, 14, 19591972.

Musolin DL (2007) Insects in a warmer world: ecological, physiological and life-history responses of true bugs (Heteroptera) to climate change. Global Change Biology, 13, $1565-1585$.

Neil K, Wu J (2006) Effects of urbanization on plant flowering phenology: A review. Urban Ecosystems, 9, 243-257.

O'Connor MI, Selig ER, Pinsky M, Altermatt F (2012) Toward a conceptual synthesis for climate change responses. Global Ecology and Biogeography, in press. DOI: 10.1111/j.1466-8238.2011.00713.x

Oke TR (1982) The energetic basis of the urban heat island. Quarterly Journal of the Royal Meteorological Society, 108, 1-24.

Parmesan C, Yohe G (2003) A globally coherent fingerprint of climate change impacts across natural systems. Nature, 421, 37-42.

Pollard E, Moss D, Yates TJ (1995) Population Trends of Common British Butterflies at Monitored Sites. Journal of Applied Ecology, 32, 9-16.

Pulliam HR (1988) Sources, sinks, and population regulation. The American Naturalist, 132, 652-661. 
R Development Core Team (2010) R: A language and environment for statistical computing. Version 2.12.1. pp Page, Vienna, Austria, R Foundation for Statistical Computing.

Roth T, Amrhein V, Peter B, Weber D (2008) A Swiss agri-environment scheme effectively enhances species richness for some taxa over time. Agriculture, Ecosystems and Envrionment, 125, 167-172.

Roy DB, Sparks TH (2000) Phenology of British butterflies and climate change. Global Change Biology, 6, 407-416.

Schar C, Vidale PL, Luthi D, Frei C, Haberli C, Liniger MA, Appenzeller C (2004) The role of increasing temperature variability in European summer heatwaves. Nature, 427, $332-336$.

Schielzeth H (2010) Simple means to improve the interpretability of regression coefficients. Methods in Ecology and Evolution, 1, 103-113.

Schweizerischer Bund Für Naturschutz (ed) (1987) Tagfalter und ihre Lebensräume, Egg/ZH, Fotorotar AG.

Stapfer A (1996) Volkszählung in der aargauischen Natur? Umwelt Argau, 6, 5-60.

Statistik Aargau (2010) Statistisches Jahrbuch 2010, Brugg, Effingerhof AG.

Steltzer H, Post E (2009) Seasons and Life Cycles. Science, 324, 886-887.

Thomas JA, Telfer MG, Roy DB et al. (2004) Comparative Losses of British Butterflies, Birds, and Plants and the Global Extinction Crisis. Science, 303, 1979-1881.

Tilman D, Fargione J, Wolff B et al. (2001) Forecasting agriculturally driven global environmental change. Science, 292, 281-284.

Travis J (2003) Climate change and habitat destruction: a deadly anthropogenic cocktail Proceeding of the Royal Society B-Biological Sciences, 270, 467-473. 
482 Van Strien AJ, Plantenga WF, Soldaat LL, Van Swaay CaM, Wallisdevries MF (2008) Bias

483

484

485

486

487

488

489

490

491

492

493

494 in phenology assessments based on first apprearance data of butterflies. Oecologia, 156, 227-235.

Walther GR, Post E, Convey P et al. (2002) Ecological responses to recent climate change. Nature, 416, 389-395.

Warren MS, Hill JK, Thomas JA et al. (2001) Rapid responses of British butterflies to opposing forces of climate and habitat change. Nature, 414, 65-69.

Weber D (2008) LANAG-Handbuch Tagfalter [in german; Manual describing sampling design, field method and quality control]. Reinach, Hintermann \& Weber AG/Abteilung Landschaft und Gewässer, Departement Bau, Verkehr und Umwelt Kanton Aargau. 


\section{Tables}

496 Table 1. Species-specific parameter estimates from the ANCOVA models on the annual date

497 of appearance relative to spring (A) and summer (B) temperature T, habitat type (agricultural,

498 forested, and settlement habitats) as well as the interaction between $\mathrm{T}$ and habitat type. The

499 intercept is the Julian date of appearance (i.e., the Julian date of the first $25 \%$ of butterflies'

500 appearance) at the mean temperature across all years. Significant and marginally significant

501 p-values $(\leq 0.1)$ are given in bold numbers. Species that start their flight period in summer

502 (June to August) are marked with a §-symbol. All other species start their flight period in

503 spring (mid-April to May).

\begin{tabular}{|c|c|c|c|c|c|c|c|c|c|}
\hline butterfly species & $\begin{array}{r}\text { slope } \\
\text { agricultura } \\
\text { I habitat }\end{array}$ & $\begin{array}{r}\text { slope } \\
\text { forested } \\
\text { habitat }\end{array}$ & $\begin{array}{r}\text { slope } \\
\text { settlement } \\
\text { habitat }\end{array}$ & $\begin{array}{r}\text { intercept } \\
\text { agricultural } \\
\text { habitat }\end{array}$ & $\begin{array}{r}\text { intercept } \\
\text { forested } \\
\text { habitat }\end{array}$ & $\begin{array}{r}\text { interce } \\
\text { pt } \\
\text { settle } \\
\text { ment } \\
\text { habitat }\end{array}$ & $\begin{array}{r}p \text {-value } \\
T\end{array}$ & $\begin{array}{r}p- \\
\text { value } \\
\text { habitat }\end{array}$ & $\begin{array}{r}\mathrm{p} \text {-value } \\
\text { interactio } \\
\mathrm{nTx} \\
\text { habitat }\end{array}$ \\
\hline Aglais urticae & 7.02 & 1.36 & -13.37 & 143.4 & 147.7 & 162.3 & 0.66 & 0.03 & 0.10 \\
\hline Anthocharis cardamines & -1.35 & -2.75 & -2.82 & 122.0 & 120.1 & 121.8 & 0.10 & 0.71 & 0.89 \\
\hline Aphantopus hyperantus & -4.11 & -5.15 & -4.43 & 191.8 & 189.6 & 191.7 & $<0.01$ & 0.69 & 0.96 \\
\hline Araschnia levana & 5.36 & -2.97 & -17.31 & 177.9 & 180.6 & 172.1 & 0.74 & 0.90 & 0.58 \\
\hline Argynnis paphia $\S$ & -7.19 & -7.43 & 13.46 & 210.3 & 199.7 & 214.8 & 0.24 & 0.12 & 0.10 \\
\hline Celastrina argiolus & -11.93 & -2.86 & -40.11 & 167.0 & 184.7 & 170.8 & 0.09 & 0.29 & 0.38 \\
\hline Coenonympha pamphilus & -10.48 & -5.01 & -12.71 & 155.7 & 143.6 & 161.2 & 0.09 & 0.22 & 0.83 \\
\hline Colias crocea $\S$ & 3.92 & 3.70 & 10.84 & 208.4 & 250.9 & 232.2 & 0.19 & 0.10 & 0.93 \\
\hline Colias hyale complex & -5.53 & -6.16 & -11.33 & 194.6 & 213.1 & 197.4 & 0.27 & 0.47 & 0.92 \\
\hline Cyaniris semiargus & -11.76 & -1.20 & -26.36 & 163.3 & 168.8 & 179.6 & 0.08 & 0.32 & 0.32 \\
\hline Cynthia cardui & 4.24 & -7.83 & -15.63 & 167.3 & 160.8 & 178.9 & 0.28 & 0.22 & 0.18 \\
\hline Gonepteryx rhamni & 5.96 & 3.97 & 12.04 & 141.8 & 137.4 & 168.8 & 0.24 & 0.05 & 0.87 \\
\hline Inachis io & 8.74 & 21.50 & 23.38 & 139.7 & 151.4 & 172.6 & 0.03 & 0.12 & 0.73 \\
\hline Lasiommata megera & -12.56 & 3.50 & 12.17 & 167.5 & 185.4 & 218.5 & 0.67 & 0.02 & 0.46 \\
\hline Leptidea sinapis complex & -4.50 & -9.61 & -11.39 & 161.1 & 160.0 & 157.4 & 0.25 & 0.94 & 0.91 \\
\hline Limenitis camilla $\S$ & -8.41 & -9.37 & 18.11 & 188.7 & 179.7 & 167.0 & 0.16 & 0.01 & $<0.01$ \\
\hline Lycaena tityrus & -27.52 & -15.32 & 4.11 & 173.8 & 175.8 & 211.4 & 0.08 & 0.53 & 0.77 \\
\hline Lysandra bellargus & -21.51 & -31.80 & 4.03 & 200.8 & 188.6 & 229.0 & 0.02 & 0.55 & 0.67 \\
\hline
\end{tabular}




\begin{tabular}{lrrrrrrrrr} 
Maniola jurtina § & -6.58 & -7.56 & 1.97 & 185.6 & 184.3 & 187.5 & $<\mathbf{0 1}$ & 0.52 & $\mathbf{0 . 0 2}$ \\
Melanargia galathea § & -5.60 & -5.97 & -5.56 & 184.2 & 181.2 & 180.1 & $<\mathbf{0 . 0 0 1}$ & 0.21 & 0.99 \\
Mellicta parthenoides & -34.46 & -15.98 & -22.50 & 176.7 & 192.0 & 180.3 & $\mathbf{0 . 0 2}$ & 0.57 & 0.75 \\
Papilio machaon & -10.52 & -14.06 & -3.37 & 156.3 & 177.8 & 177.4 & 0.32 & 0.35 & 0.88 \\
Pararge aegeria & -3.46 & -1.63 & -16.08 & 154.7 & 150.1 & 152.4 & 0.24 & 0.91 & 0.55 \\
Pieris sp. & -6.85 & -5.68 & -8.12 & 177.5 & 166.8 & 182.7 & 0.12 & 0.15 & 0.97 \\
Polygonia c-album & -3.50 & 1.22 & -1.83 & 184.0 & 170.1 & 206.2 & 0.76 & $\mathbf{0 . 0 3}$ & 0.94 \\
Polyommatus icarus & -12.83 & -6.70 & -15.61 & 175.0 & 164.7 & 185.0 & $\mathbf{0 . 0 6}$ & 0.21 & 0.82 \\
Vanessa atalanta & -3.79 & -15.53 & -4.35 & 197.0 & 193.5 & 214.1 & 0.11 & $\mathbf{0 . 0 5}$ & 0.49 \\
Zygaena filipendulae $\S$ & 11.91 & 19.70 & 10.05 & 199.9 & 198.7 & 211.8 & 0.11 & 0.63 & 0.88 \\
\hline
\end{tabular}

B) summer

\begin{tabular}{|c|c|c|c|c|c|c|c|c|c|}
\hline butterfly species & $\begin{array}{r}\text { slope } \\
\text { agricultura } \\
\text { I habitat }\end{array}$ & $\begin{array}{r}\text { slope } \\
\text { forested } \\
\text { habitat }\end{array}$ & $\begin{array}{r}\text { slope } \\
\text { settlement } \\
\text { habitat }\end{array}$ & $\begin{array}{r}\text { intercept } \\
\text { agricultural } \\
\text { habitat }\end{array}$ & $\begin{array}{r}\text { intercept } \\
\text { forested } \\
\text { habitat }\end{array}$ & $\begin{array}{r}\text { interce } \\
\text { pt } \\
\text { settle } \\
\text { ment } \\
\text { habitat }\end{array}$ & $\begin{array}{r}\text { p-value } \\
T\end{array}$ & $\begin{array}{r}p- \\
\text { value } \\
\text { habitat }\end{array}$ & $\begin{array}{r}\text { p-value } \\
\text { interactio } \\
\mathrm{n} \mathrm{Tx} \\
\text { habitat }\end{array}$ \\
\hline Aglais urticae & -0.48 & -1.22 & 0.34 & 143.4 & 147.6 & 163.4 & 0.89 & 0.05 & 0.98 \\
\hline Anthocharis cardamines & -0.99 & -1.32 & -1.68 & 122.0 & 120.1 & 121.9 & 0.20 & 0.70 & 0.96 \\
\hline Aphantopus hyperantus & -2.71 & -4.35 & 2.00 & 191.8 & 189.6 & 191.7 & 0.15 & 0.70 & 0.08 \\
\hline Araschnia levana & 6.66 & -9.64 & 63.86 & 178.1 & 180.6 & 184.6 & 0.80 & 0.89 & 0.03 \\
\hline Argynnis paphia $\S$ & -2.10 & -6.15 & -23.94 & 211.4 & 199.7 & 209.7 & 0.09 & 0.10 & 0.35 \\
\hline Celastrina argiolus & -4.83 & 21.45 & -1.24 & 167.7 & 190.1 & 190.9 & 0.49 & 0.27 & 0.60 \\
\hline Coenonympha pamphilus & 0.62 & 3.92 & 21.10 & 155.8 & 143.6 & 161.3 & 0.02 & 0.15 & 0.05 \\
\hline Colias crocea $\S$ & 11.44 & -9.59 & -31.26 & 206.2 & 252.1 & 220.8 & 0.60 & 0.03 & 0.38 \\
\hline Colias hyale complex & -0.10 & 28.01 & 2.06 & 194.6 & 217.9 & 196.6 & 0.85 & 0.50 & 0.70 \\
\hline Cyaniris semiargus & -1.72 & -4.36 & -7.28 & 163.3 & 168.8 & 178.3 & 0.43 & 0.41 & 0.95 \\
\hline Cynthia cardui & -8.02 & -3.60 & -4.25 & 167.3 & 163.5 & 178.1 & 0.10 & 0.33 & 0.84 \\
\hline Gonepteryx rhamni & 9.70 & 4.64 & -1.33 & 139.8 & 137.4 & 169.6 & 0.25 & 0.05 & 0.64 \\
\hline Inachis io & 3.79 & -14.89 & 2.58 & 139.7 & 151.3 & 172.9 & 0.68 & 0.14 & 0.42 \\
\hline Lasiommata megera & -6.77 & -0.66 & -28.85 & 169.5 & 185.4 & 218.5 & 0.30 & 0.03 & 0.71 \\
\hline Leptidea sinapis complex & 3.61 & -8.27 & 2.07 & 161.1 & 158.1 & 154.9 & 0.74 & 0.85 & 0.53 \\
\hline Limenitis camilla $\S$ & -3.09 & -2.60 & 1.82 & 186.9 & 179.8 & 160.6 & 0.20 & 0.10 & 0.70 \\
\hline Lycaena tityrus & 14.10 & -6.36 & -19.41 & 173.6 & 180.7 & 206.3 & 0.33 & 0.34 & 0.86 \\
\hline Lysandra bellargus & -26.08 & 23.82 & -2.19 & 192.5 & 193.9 & 226.6 & 0.74 & 0.46 & 0.64 \\
\hline Maniola jurtina § & -2.22 & -3.89 & -0.15 & 185.6 & 184.3 & 187.5 & 0.10 & 0.61 & 0.47 \\
\hline Melanargia galathea $\S$ & -2.62 & -2.15 & -0.41 & 184.2 & 181.2 & 180.2 & 0.13 & 0.35 & 0.70 \\
\hline
\end{tabular}


Altermatt

\begin{tabular}{lrrrrrrrrr} 
Mellicta parthenoides & 27.14 & 76.91 & -29.53 & 184.3 & 197.8 & 157.5 & 0.33 & 0.91 & 0.19 \\
Papilio machaon & 2.37 & 32.46 & 14.00 & 156.3 & 183.8 & 180.9 & 0.71 & 0.33 & 0.68 \\
Pararge aegeria & -6.71 & -5.99 & 14.46 & 154.6 & 150.1 & 152.5 & 0.88 & 0.92 & $\mathbf{0 . 0 7}$ \\
Pieris sp. & -2.19 & 2.15 & 0.17 & 177.5 & 166.8 & 182.8 & 0.99 & 0.17 & 0.87 \\
Polygonia c-album & -6.62 & 0.41 & -15.60 & 184.5 & 170.1 & 211.6 & 0.15 & $<0.01$ & 0.22 \\
Polyommatus icarus & 10.09 & 7.56 & 7.15 & 175.0 & 164.7 & 185.1 & $\mathbf{0 . 0 8}$ & 0.22 & 0.96 \\
Vanessa atalanta & -2.44 & -5.44 & -5.44 & 197.0 & 193.5 & 213.8 & 0.20 & $\mathbf{0 . 0 7}$ & 0.92 \\
Zygaena filipendulae § & -12.82 & -30.79 & 4.84 & 199.4 & 188.4 & 213.7 & $\mathbf{0 . 0 8}$ & 0.82 & 0.76 \\
\hline
\end{tabular}

504

505 


\section{Figure Headings}

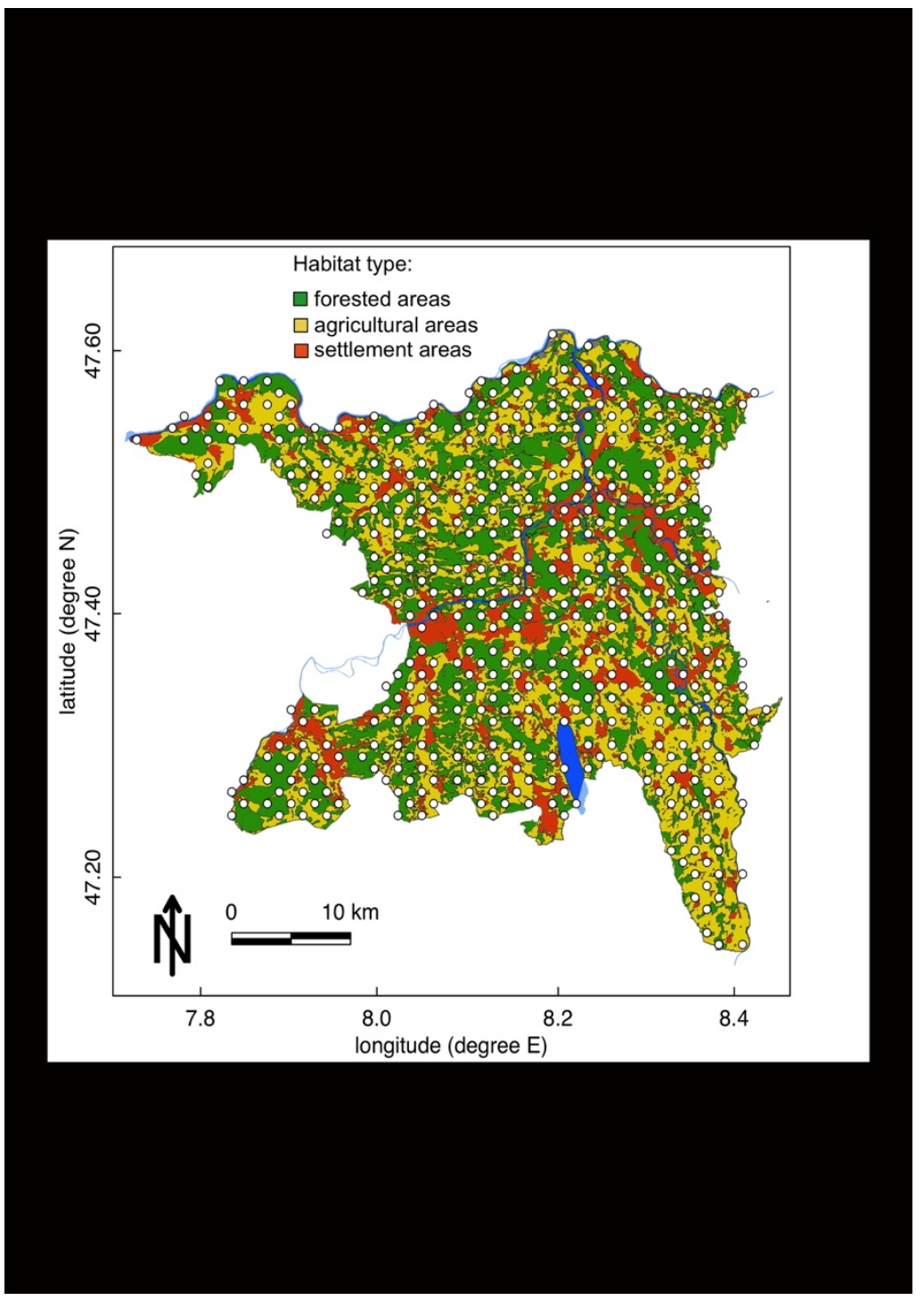

508 Fig. 1. Map of the canton of Aargau (Switzerland) showing the 519 transect localities (white

509 dots) used in this study. The different habitat types are given in colour: forested (green),

510 agricultural (yellow) and settlement areas (red); lakes and large rivers are in blue. 


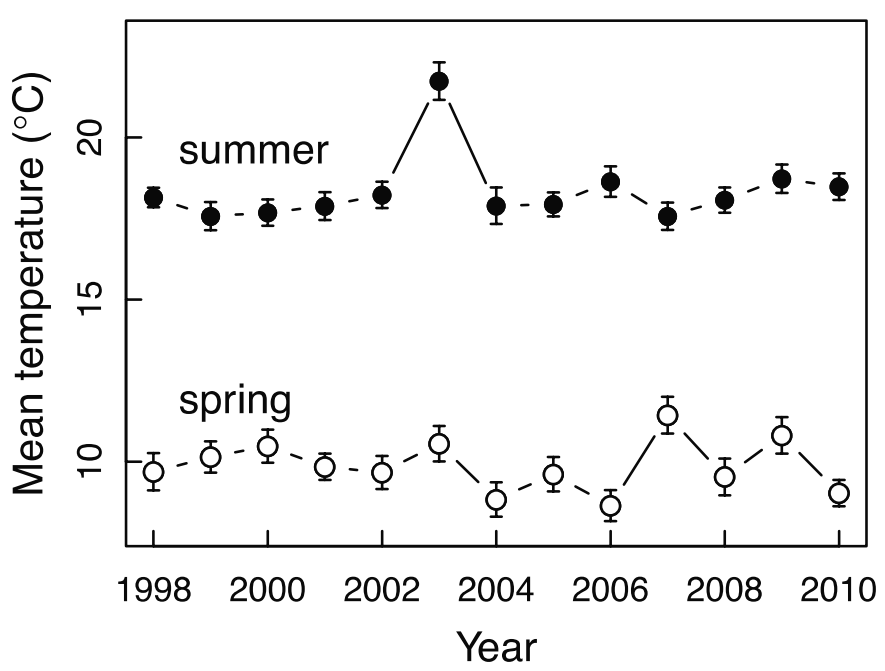

512 Fig. 2. Annual spring (March to May, white dots) and summer (June to August, black dots)

513 air-temperature for the canton of Aargau. Mean \pm se value of three different weather stations.

514 There was no significant change in mean temperature over the study period from 1998-2010,

515 but there was considerable inter-annual variation, especially in spring.

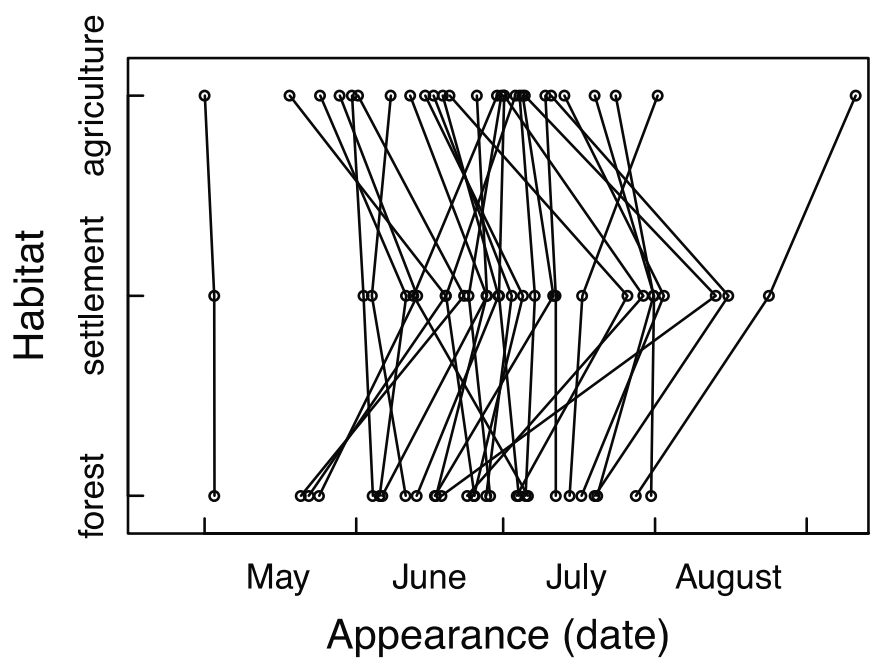

517 Fig. 3. Appearance (date of $25 \%$ percentile of all individuals of a species observed, mean

518 across all years) of 28 butterfly species across the three habitat types. For each species, the values across different habitats are connected with a line. 


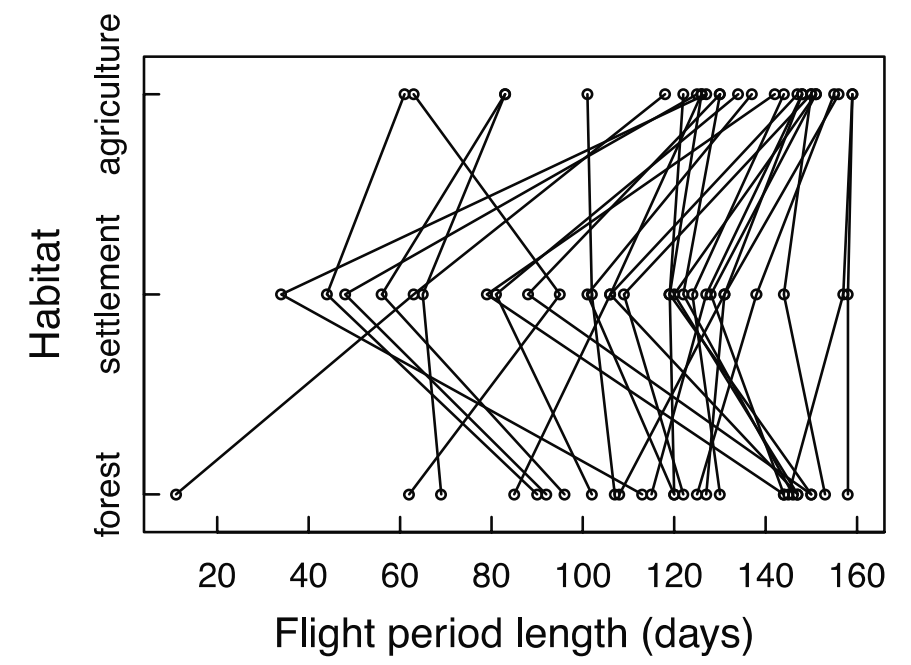

521 Fig. 4. Flight period length of 28 butterfly species across the three habitat types. For each

522 species, the values across different habitats are connected with a line.

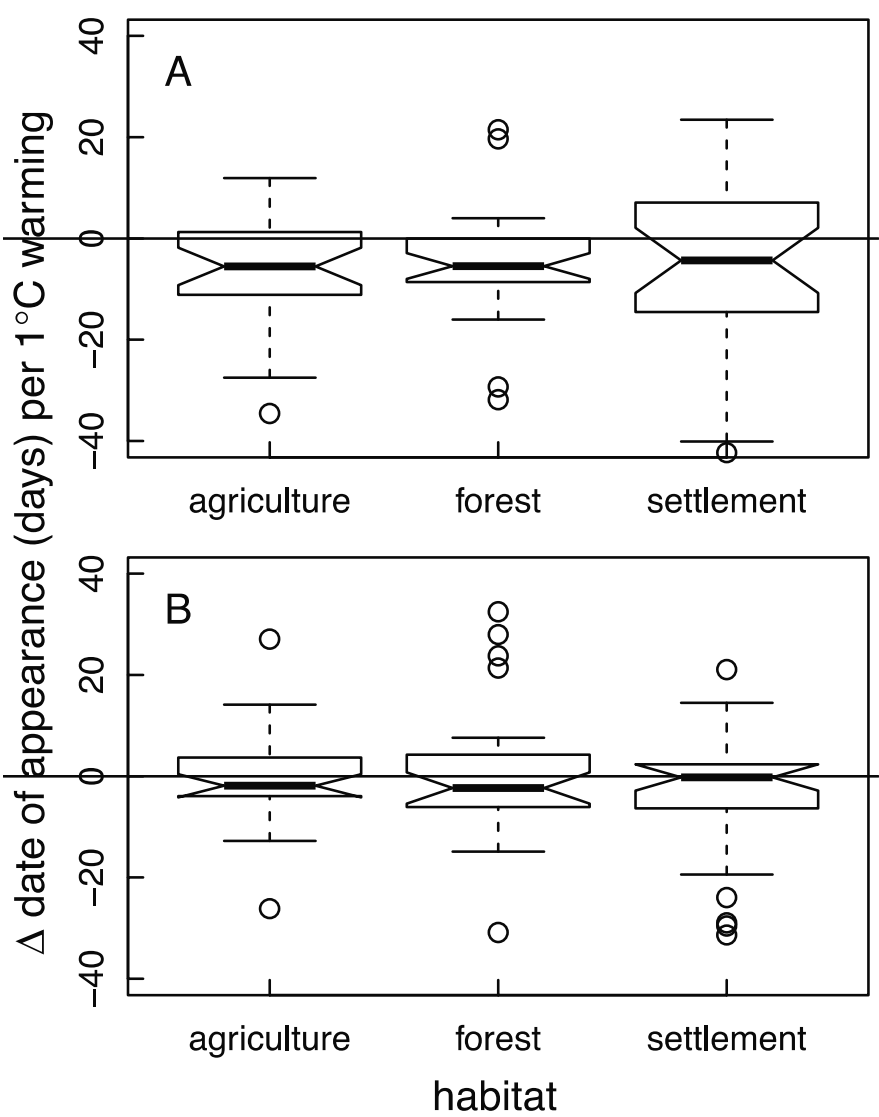

524 Fig. 5. Predicted shift (in days) of the date of appearance of all 28 butterfly species in the

525 different habitat types per $1^{\circ} \mathrm{C}$ of warming in spring (A) and summer (B). The predictions are

526 taken from the parameter values of the ANCOVA models (table 1). The thick line in the 
527 boxplots gives the median, the box is the interquartile range, and whiskers extend to the most 528 extreme data point that is no more than 1.5 times the interquartile range. 